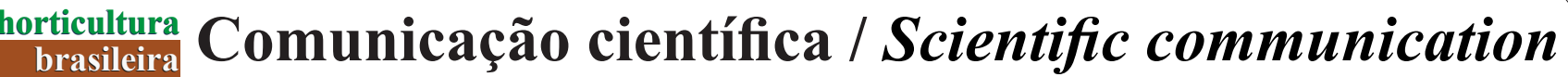

ARMONDES, KAP; DIAS, DCFS; MARTINEZ, PAH; SILVA, LJ; HILST, PC. 2016. Condicionamento osmótico e desempenho de sementes de repolho com diferentes níveis de vigor. Horticultura Brasileira 34: 428-434. DOI - http://dx.doi.org/10.1590/S0102-05362016003020

\section{Condicionamento osmótico e desempenho de sementes de repolho com diferentes níveis de vigor}

\author{
Kássia AP Armondes; Denise CFS Dias; Paola AH Martínez; Laércio J Silva; Paulo C Hilst \\ Universidade Federal de Viçosa (UFV), Depto. Fitotecnia, Viçosa-MG, Brasil; kassiaarmondes@yahoo.com.br; dcdias@ufv.br; \\ pahoma@gmail.com; laercio.silva@ufv.br; pchilst@yahoo.com.br
}

\begin{abstract}
RESUMO
O condicionamento osmótico de sementes vem sendo indicado como alternativa para uniformizar e acelerar a germinação e a emergência de plântulas, especialmente em hortaliças. Assim, objetivou-se avaliar o efeito do condicionamento osmótico sobre o desempenho de lotes de sementes de repolho com diferentes níveis de vigor. Foram utilizadas sementes de quatro lotes de repolho, cultivar 60 dias. No primeiro ensaio, as sementes foram condicionadas em solução aerada de PEG 6000 a -1,0 MPa por 0, 2, 4 e 6 dias, a $20^{\circ} \mathrm{C}$. As sementes de cada tratamento, submetidas ou não a secagem até atingir novamente o teor de água inicial, foram avaliadas mediante testes de germinação e de emergência de plântulas em casa de vegetação. Num segundo ensaio, sementes da mesma cultivar foram submetidas ao envelhecimento artificial a $42^{\circ} \mathrm{C}$ e $100 \%$ U.R. por $0,24,33$ e $42 \mathrm{~h}$ e, em seguida, submetidas ao condicionamento em solução de PEG 6000 a $-1,0 \mathrm{MPa}$, a $20^{\circ} \mathrm{C}$, por seis dias, sendo secadas em seguida. $\mathrm{O}$ condicionamento osmótico em PEG 6000, a -1,0 MPa por seis dias, beneficia a germinação e o vigor de sementes de repolho, de maneira mais evidente em lotes de menor qualidade fisiológica.
\end{abstract}

Palavras-chave: Brassica oleracea var. capitata, osmocondicionamento, qualidade fisiológica, germinação.

\begin{abstract}
Osmopriming and performance of cabbage seeds with different levels of vigor

Priming, used as a pre-sowing treatment, has been recommended as an alternative to increase speed and uniformity of seed germination and seedling emergence, especially for vegetable seeds. The effect of osmopriming on performance of cabbage seed lots with different levels of vigor was evaluated. Four seed lots of cabbage ' 60 dias' were used. Seeds of each lot were primed in aerated -1.0 MPa PEG 6000 solution for $0,2,4$ and 6 days at $20^{\circ} \mathrm{C}$. Seeds of each treatment, dried or not after priming, were evaluated by germination test and seedling emergence in greenhouse. In a second assay, cabbage seeds were submitted to artificial aging at $42^{\circ} \mathrm{C}$ and $100 \%$ relative humidity for $0,24,33$ and $42 \mathrm{~h}$ and, after that, submitted to osmopriming, as described, for six days, and subsequently dried to attain the original seed water content. Priming in 6000 PEG solution at -1,0 MPa for six days is efficient to improve germination of cabbage seeds, especially for low vigor seed lots.
\end{abstract}

Keywords: Brassica oleracea var. capitata, osmopriming, physiological quality, germination.

\section{(Recebido para publicação em 4 de junho de 2015; aceito em 22 de abril de 2016) (Received on June 4, 2015; accepted on April 22, 2016)}

\begin{abstract}
A germinação rápida e uniforme é importante porque reduz a exposição das sementes e das plântulas às intempéries em campo. Em culturas de ciclo relativamente curto, como as hortaliças, o período de tempo compreendido entre a semeadura e a emergência das plântulas representa uma das fases críticas do ciclo das plantas, de modo que a uniformidade e a porcentagem de emergência assumem grande importância na produção e qualidade final do produto (Dias et al., 1999).

A obtenção de população adequada e uniforme de plantas em campo é um dos principais fatores determinantes da qualidade final do produto olerícola
\end{abstract}

(Marcos-Filho \& Kikuti, 2008), a qual pode ser influenciada pela qualidade fisiológica das sementes utilizadas. Geralmente, as sementes de repolho não são semeadas diretamente no campo, sendo comumente utilizadas para a produção de mudas. Essa é uma das etapas mais importantes no sistema de produção dessa cultura, tendo relação direta com a produtividade, podendo ser reduzida quando se utiliza mudas de baixa qualidade. Nesse sentido, a utilização de sementes de repolho com elevada qualidade fisiológica tem sido considerada responsável pelo melhor estabelecimento e uniformidade das mudas e, além disso, deu origem a plantas mais produtivas (Finch-Savage \& McKee, 1990).

Resultados obtidos por Powell et al. (1991), comparando lotes de sementes de algumas brássicas, incluindo o repolho, com diferentes níveis de vigor, comprovaram que a utilização de sementes menos vigorosas é prejudicial para a formação das mudas e para o estabelecimento das culturas. Segundo esses autores, sementes com baixo vigor resultaram em mudas desuniformes quanto ao tamanho e à massa seca e, além disso, tiveram a emergência mais lenta e desuniforme.

Nesse sentido, justifica-se o uso de tratamentos pré-semeadura que permi- 
tam acelerar a emergência das plântulas, resultando em maior segurança quanto à obtenção de populações desejadas de plantas por área, especialmente sob condições adversas (Pereira et al., 2008). Dentre estas técnicas, destaca-se o condicionamento osmótico (Parera \& Cantliffe, 1994) que consiste em embeber as sementes em uma solução osmótica por determinado período de tempo, de modo a promover uma hidratação controlada, reativando as fases iniciais da germinação (fases I e II) sem, contudo, atingir o estádio de emergência da raiz primária (fase III), segundo o padrão trifásico de embebição proposto por Bewley \& Black (1994).

Diversos fatores determinam o sucesso do condicionamento fisiológico, podendo-se citar a qualidade fisiológica inicial das sementes (Kikuti \& Marcos-Filho, 2009), o período e a temperatura de condicionamento (Nascimento, 2004), o potencial osmótico da solução (Gomes et al., 2012), bem como o agente osmótico. Quando são utilizadas substâncias de alto peso molecular e quimicamente inertes como o PEG, pode ser necessária a aeração artificial durante o condicionamento, visto que a maior viscosidade causa uma diminuição de permeabilidade ao oxigênio (Nascimento, 2004).

O nível de deterioração do lote de sementes é um dos fatores que pode influenciar significativamente o efeito do condicionamento. Segundo Bittencourt et al. (2005), essa técnica permitiu obter maior porcentagem de germinação em sementes de aspargo com baixa qualidade fisiológica, apresentando efeito mais significativo nos lotes de médio e baixo nível de desempenho, em comparação a lotes mais vigorosos.

Além disso, após o osmocondicionamento, as sementes podem ser secadas até atingir novamente o grau de umidade inicial, o que permite o manuseio e/ou armazenamento por períodos curtos sem perder a viabilidade (Nascimento, 2005). Existem controvérsias relacionadas ao efeito da secagem logo após o condicionamento osmótico (Caseiro \& Marcos-Filho, 2005). Em alguns estudos, autores emitiram a opinião de que a secagem reverte efeitos benéficos do osmocondicionamento (Rowse, 1996), enquanto, em outros, os resultados foram favoráveis (Fanan \& Novembre, 2007; Gomes et al., 2012), ou seja, mesmo após a secagem, as sementes submetidas ao condicionamento apresentaram melhor desempenho comparadas às não condicionadas. Deve ser considerado, sempre, que logo após o condicionamento as sementes estão relativamente úmidas o que favorece a velocidade de germinação, em relação às sementes mais secas. Desta forma, essa ocorrência pode estar mais relacionada a efeitos do teor de água sobre a velocidade de germinação ou de emergência de plântulas e não à possível reversão de efeitos do condicionamento.

Assim, o tratamento de condicionamento osmótico em sementes de repolho pode ser uma técnica viável, a fim de contribuir para a produção mais rápida de mudas de melhor qualidade. Nesse sentido, segundo dados levantados por Nascimento (2004), o tratamento indicado para o condicionamento fisiológico de sementes dessa espécie é a solução de $\mathrm{PEG}$, durante sete dias, a $15^{\circ} \mathrm{C}$, porém sem nenhuma referência quanto à concentração do agente osmótico e quanto à recomendação ou não da secagem das sementes após o tratamento. Diante disto, o objetivo do trabalho foi avaliar o desempenho de sementes de repolho, com diferentes níveis de qualidade, após o condicionamento osmótico com solução de PEG, por diferentes períodos, seguido ou não de secagem das sementes.

\section{MATERIAL E MÉTODOS}

O trabalho foi realizado no Laboratório de Sementes do Departamento de Fitotecnia da Universidade Federal de Viçosa, constando de dois ensaios.

\section{Ensaio 1}

Foram utilizados quatro lotes de sementes de repolho, cultivar 60 dias, apresentando diferentes níveis de qualidade fisiológica. As sementes de cada lote foram condicionadas em solução de polietileno glicol 6000 (PEG 6000) com potencial osmótico ajustado a $-1,0 \mathrm{MPa}$, na concentração de $284 \mathrm{~g} / \mathrm{L}$, a $20^{\circ} \mathrm{C}$, durante 6 dias. Seguiu-se a metodologia proposta por Pereira et al. (2008), que consistiu em manter as sementes em solução aerada. Neste método, $4,0 \mathrm{~g}$ de sementes foram colocadas em erlenmeyers (250 mL) contendo 40,0 mL de solução osmótica. Os erlenmeyers foram tampados com rolha de borracha, acoplada a uma bomba de aquário para promover a aeração das soluções. O sistema foi mantido em incubadora BOD a $20^{\circ} \mathrm{C}$, durante dois, quatro e seis dias. Logo após o condicionamento, as sementes foram submetidas à determinação do grau de umidade em estufa, a $105 \pm 3^{\circ} \mathrm{C}$, durante 24 horas (Brasil, 2009).

As sementes de cada lote foram divididas em duas porções. A primeira foi submetida à secagem artificial, em estufa regulada a $25^{\circ} \mathrm{C}$, com ventilação forçada, até atingir grau de umidade próximo ao inicial do lote (antes do condicionamento). A outra porção não sofreu secagem e foi submetida às avaliações logo após o condicionamento osmótico.

Os tratamentos consistiram na combinação dos tempos de condicionamento (2, 4 e 6 dias) e do uso ou não da secagem, além de uma testemunha não condicionada. As sementes de cada lote, com e sem secagem, foram, então, avaliadas quanto à qualidade fisiológica:

Germinação - realizado com quatro repetições de 50 sementes para cada lote, dispostas sobre três folhas de papel toalha umedecido com água destilada na proporção de 2,5 vezes o peso do papel seco, em caixas de plástico (gerbox). As caixas foram mantidas em germinador a $20^{\circ} \mathrm{C}$. A avaliação foi realizada no quinto (primeira contagem) e no décimo dia após a instalação do teste (Brasil, 2009). Esses resultados foram expressos em porcentagem de plântulas normais. Paralelamente, efetuaram-se contagens diárias do número de plântulas normais para o cálculo do índice de velocidade de germinação para cada lote, conforme Maguire (1962).

Emergência de plântulas - conduzida em casa de vegetação, com quatro repetições de 50 sementes, distribuídas em bandejas de plástico contendo substrato comercial à base de fibra de coco. O substrato foi umedecido até atingir $60 \%$ da capacidade de retenção de água e, sempre que necessário, foram efetuadas irrigações. Realizaram-se contagens diárias do número de plântulas 
emergidas até a sua estabilização, o que ocorreu aos 12 dias após a semeadura. Os dados obtidos nas contagens diárias foram utilizados para o cálculo do índice de velocidade de emergência de plântulas (IVE), conforme Maguire (1962). Calculou-se também a porcentagem de plântulas emergidas de cada lote, aos 12 dias após o início do teste.

Análise estatística - o delineamento experimental utilizado foi inteiramente casualizado, com quatro repetições. Os pressupostos de normalidade e homogeneidade de variância para os dados obtidos foram testados por meio do teste de Shapiro-Wilk e pelo teste de Hartley. Como os dados apresentaram distribuição normal, eles foram submetidos à análise de variância e as médias obtidas para os tratamentos foram comparadas pelo teste de Tukey ( $5 \%$ de probabilidade).

\section{Ensaio 2}

Foram utilizadas sementes de repolho cultivar 60 dias previamente envelhecidas artificialmente. Para tanto, as sementes foram distribuídas em camada única sobre tela acoplada a caixas de plástico (gerbox) contendo $40 \mathrm{~mL}$ de água destilada. As caixas foram tampadas, obtendo-se cerca de $100 \%$ de umidade relativa em seu interior, e mantidas em incubadora BOD a $42^{\circ} \mathrm{C}$, por 0,24 , 33 e 42 h. Foram então obtidos quatro lotes com diferentes níveis de deterioração, ou seja, diferentes níveis de vigor. Após o envelhecimento artificial, as sementes foram secadas em laboratório $\left(25^{\circ} \mathrm{C}\right)$, até atingirem aproximadamente $7,5 \%$ de umidade.

Após o envelhecimento e a secagem, sementes de cada lote foram condicionadas osmoticamente em solução aerada de PEG 6000 a -1,0 MPa, a $20^{\circ} \mathrm{C}$, durante 6 dias, sendo submetidas a nova secagem logo após o condicionamento, conforme definido pelo Ensaio 1. As sementes de cada lote foram então submetidas aos testes de germinação e de emergência de plântulas, adotando-se os procedimentos descritos no Ensaio 1.

Análise estatística - o delineamento experimental utilizado foi inteiramente casualizado, com quatro repetições, em esquema fatorial $4 \times 2$ (períodos de envelhecimento artificial $\mathrm{x}$ com ou sem condicionamento). Os pressupostos de normalidade e homogeneidade de variância para os dados obtidos foram testados por meio do teste de Shapiro-Wilk e pelo teste de Hartley. Como os dados apresentaram distribuição normal, eles foram submetidos à análise de variância e a comparação das médias obtidas nos tratamentos de condicionamento e de envelhecimento foi realizada pelos testes $\mathrm{F}$ e de Tukey, respectivamente, a $5 \%$ de probabilidade.

\section{RESULTADOS E DISCUSSÃO}

\section{Ensaio 1}

A caracterização inicial da qualidade fisiológica das sementes dos quatro lotes utilizados no experimento encontra-se na Tabela 1. Em geral, considerando os resultados da maioria dos testes aplicados, pode-se afirmar que os lotes 1 e 2 apresentaram qualidade fisiológica superior, em relação aos lotes 3 e 4 . Segundo Kikuti \& Marcos-Filho (2009), a utilização de lotes com diferenças no potencial fisiológico permite verificar o grau de consistência da aplicação dos métodos empregados para o condicionamento fisiológico das sementes.

Pela Tabela 2, observa-se que a porcentagem de germinação dos lotes 1 e 2 não diferiu entre os tratamentos e a testemunha não condicionada. Para as sementes do lote 3 , o osmocondicionamento por quatro e seis dias foi benéfico à germinação, independentemente da secagem ou não das sementes após o tratamento. Para as sementes do lote 4, o condicionamento osmótico por seis dias sem secagem das sementes foi superior à testemunha não condicionada e destacou-se também em relação aos demais tratamentos de condicionamento empregados, não diferindo apenas do tratamento de condicionamento por seis dias seguido de secagem (Tabela 2).

O sucesso do condicionamento osmótico depende, dentre outros fatores, da qualidade inicial do lote (Pereira et al., 2008). Em geral, lotes de alta qualidade fisiológica não respondem satisfatoriamente ao tratamento, por apresentarem germinação rápida e uniforme. Entretanto, o condicionamento osmótico tem uniformizado e acelerado a germinação de lotes de sementes de baixa qualidade fisiológica de algumas espécies (Bittencourt et al., 2005; Pereira et al., 2008). No presente trabalho, o lote de sementes com menor qualidade fisiológica, que inicialmente possuía $71 \%$ de germinação, atingiu $82 \%$ de germinação, quando as sementes foram condicionadas por seis dias sem secagem.

Pela primeira contagem de germinação (Tabela 2), observa-se que as sementes dos lotes considerados de maior vigor (lotes 1 e 2) também não sofreram influência dos tratamentos de condicionamento osmótico, assim como observado para os resultados de germinação. Enquanto que o osmocondicionamento por quatro e seis dias, para o lote 3 , e por seis dias para o lote 4 , ambos com e sem secagem, promoveram maiores valores no teste de primeira contagem de germinação. A primeira contagem de germinação pode ser utilizada como um indicativo da velocidade de germinação. Deste modo, pode-se afirmar que o condicionamento osmótico foi eficiente para acelerar a germinação das sementes destes lotes.

Parera \& Cantliffe (1994) sugeriram que o uso de lotes de alto vigor é essencial para se obter resultados satisfatórios com o condicionamento osmótico, o que não tem sido constatado na maioria dos estudos de condicionamento osmótico envolvendo lotes de diferentes níveis de qualidade (Bittencourt et al., 2005; Fanan \& Novembre, 2007; Kikuti \& Marcos-Filho, 2009; Gomes et al., 2012). Assim, no presente trabalho, verifica-se que o condicionamento osmótico foi efetivo para as sementes de média e baixa qualidade fisiológica (lotes 3 e 4, respectivamente), em acelerar a germinação, conforme observado pelos valores obtidos para a primeira contagem de germinação. Nota-se também que, tanto para a porcentagem final de germinação quanto para a primeira contagem de germinação (Tabela 2), o condicionamento osmótico das sementes por seis dias, seguido ou não de secagem, foi benéfico.

Os valores de IVG (Tabela 2) também foram influenciados pelos tratamentos de condicionamento fisiológico. Apenas para as sementes do lote 1 não foi observado efeito dos tratamentos; 
já para as sementes dos demais lotes, destaca-se o condicionamento com PEG 6000 a -1,0 MPa por seis dias. Maiores valores de IVG indicam que a germinação se deu de forma mais rápida, o que nesse caso está associado à eficiência do tratamento em uniformizar e acelerar a germinação das sementes, previamente embebidas e ainda apresentando grau de umidade elevado, já que não foram

Tabela 1. Caracterização inicial da qualidade fisiológica das sementes dos quatro lotes de repolho, cultivar 60 dias: porcentagem de germinação (GER), primeira contagem de germinação (PC), índice de velocidade de germinação (IVG), porcentagem de emergência de plântulas (EME) e índice de velocidade de emergência de plântulas (IVE) \{initial characterization of the seed phisiological quality of four seed lots of cabbage cultivar 60 dias: percentage of germination (GER), first count of germination (PC), germination speed index (IVG), percentage of seedling emergence (EME) and seedling emergence speed index (IVE)\}. Viçosa, UFV, 2014.

\begin{tabular}{lccccl}
\hline Lote & GER (\%) & PC (\%) & IVG & EME (\%) & IVE \\
\hline 1 & $94 \mathrm{a}$ & $85 \mathrm{a}$ & $11,98 \mathrm{a}$ & $83 \mathrm{ab}$ & $3,66 \mathrm{ab}$ \\
2 & $90 \mathrm{ab}$ & $82 \mathrm{ab}$ & $11,76 \mathrm{a}$ & $91 \mathrm{a}$ & $4,14 \mathrm{a}$ \\
3 & $84 \mathrm{~b}$ & $71 \mathrm{~b}$ & $11,21 \mathrm{a}$ & $59 \mathrm{c}$ & $1,68 \mathrm{c}$ \\
4 & $71 \mathrm{c}$ & $43 \mathrm{c}$ & $7,51 \mathrm{~b}$ & $77 \mathrm{~b}$ & $3,41 \mathrm{~b}$ \\
\hline CV (\%) & 5,16 & 8,23 & 7,22 & 7,80 & 9,56 \\
\hline
\end{tabular}

Médias seguidas pela mesma letra na coluna não diferem estatisticamente entre si pelo teste de Tukey a $5 \%$ de probabilidade (means followed by the same letter in column do not differ from each other according to Tukey's test, at $5 \%$ probability).

submetidas à secagem. Além disso, durante o tratamento de condicionamento, com a absorção de água, as sementes têm o metabolismo reativado, ocorre o processo bioquímico preparatório para a germinação, sendo que após o tratamento as sementes germinam rapidamente (Bray, 1995). Isso explica o efeito desse tratamento ser evidente nos lotes de menor qualidade fisiológica (lotes 3 e 4), que em geral demandam mais tempo para concluir esse processo.

Na Tabela 2, observa-se maior velocidade de germinação e maior porcentagem de germinação dos lotes com menor qualidade fisiológica. $\mathrm{O}$ condicionamento osmótico consiste na embebição controlada das sementes e, durante esse tratamento, ocorre a reativação do metabolismo. Com isso, as sementes ativam mecanismos de reparo das membranas celulares, de síntese de proteínas e de mobilização de açúcares e proteínas (Srinivasan et al., 1999), fazendo com que, após o tratamento,

Tabela 2. Porcentagem de germinação (GER), primeira contagem de germinação (PC), índice de velocidade de germinação (IVG) e porcentagem de emergência de plântulas (EME) provenientes de sementes de quatro lotes de repolho, cultivar 60 dias, submetidas a diferentes tratamentos de condicionamento osmótico seguido (CS) ou não de secagem (SS) \{percentage of germination (GER), first count of germination (PC), germination speed index (IVG) and percentage of seedling emergence (EME) from seeds of four seed lots of cabbage cultivar 60 dias, submitted to different priming treatments followed (CS) or not (SS) by drying\}. Viçosa, UFV, 2014.

\begin{tabular}{|c|c|c|c|c|c|c|c|c|}
\hline \multirow{2}{*}{ Tratamento } & \multicolumn{4}{|c|}{ GER (\%) } & \multicolumn{4}{|c|}{ PC (\%) } \\
\hline & L 1 & L 2 & L 3 & L 4 & L 1 & L 2 & L 3 & L 4 \\
\hline Testemunha & $94 \mathrm{a}$ & $90 \mathrm{a}$ & $84 \mathrm{~b}$ & $71 \mathrm{bc}$ & $85 \mathrm{a}$ & $90 \mathrm{a}$ & $84 \mathrm{~b}$ & $43 \mathrm{~b}$ \\
\hline 2 dias SS & $93 \mathrm{a}$ & $89 \mathrm{a}$ & $89 \mathrm{ab}$ & $57 \mathrm{~d}$ & 89 a & $89 a$ & $89 \mathrm{ab}$ & $46 \mathrm{~b}$ \\
\hline 4 dias SS & $90 \mathrm{a}$ & $90 \mathrm{a}$ & $91 \mathrm{a}$ & $67 \mathrm{c}$ & $85 \mathrm{a}$ & $90 \mathrm{a}$ & $91 \mathrm{a}$ & $58 \mathrm{ab}$ \\
\hline 6 dias SS & $91 \mathrm{a}$ & $95 \mathrm{a}$ & $93 \mathrm{a}$ & $82 \mathrm{a}$ & $82 \mathrm{a}$ & $95 \mathrm{a}$ & $93 \mathrm{a}$ & $62 \mathrm{a}$ \\
\hline 2 dias CS & $95 \mathrm{a}$ & $93 \mathrm{a}$ & $89 \mathrm{ab}$ & $67 \mathrm{c}$ & $86 a$ & $93 \mathrm{a}$ & $89 \mathrm{ab}$ & $51 \mathrm{ab}$ \\
\hline 4 dias CS & $92 \mathrm{a}$ & $89 \mathrm{a}$ & $92 \mathrm{a}$ & $71 \mathrm{bc}$ & $81 \mathrm{a}$ & $89 a$ & $92 \mathrm{a}$ & $51 \mathrm{ab}$ \\
\hline 6 dias CS & $92 \mathrm{a}$ & $88 \mathrm{a}$ & $95 \mathrm{a}$ & $78 \mathrm{ab}$ & $89 \mathrm{a}$ & $88 \mathrm{a}$ & $95 \mathrm{a}$ & $62 \mathrm{a}$ \\
\hline \multirow[t]{2}{*}{ CV (\%) } & 4,55 & 5,04 & 3,36 & 8,86 & 7,00 & 5,78 & 5,80 & 13,19 \\
\hline & \multicolumn{4}{|c|}{ IVG } & \multicolumn{4}{|c|}{ EME (\%) } \\
\hline Testemunha & $11,97 \mathrm{a}$ & $11,76 \mathrm{bc}$ & $11,21 \mathrm{c}$ & $7,51 \mathrm{c}$ & $83 a b$ & $91 \mathrm{a}$ & $59 \mathrm{c}$ & $77 \mathrm{a}$ \\
\hline 2 dias SS & $13,95 \mathrm{a}$ & $13,06 \mathrm{ab}$ & $15,41 \mathrm{~b}$ & $6,42 \mathrm{c}$ & $45 \mathrm{c}$ & $80 \mathrm{a}$ & $68 \mathrm{bc}$ & $83 \mathrm{a}$ \\
\hline 4 dias SS & $12,76 \mathrm{a}$ & $13,00 \mathrm{ab}$ & $15,10 \mathrm{~b}$ & $9,33 \mathrm{ab}$ & $79 \mathrm{~b}$ & $92 \mathrm{a}$ & $76 \mathrm{ab}$ & $81 \mathrm{a}$ \\
\hline 6 dias SS & $13,87 \mathrm{a}$ & $14,73 \mathrm{a}$ & $19,35 \mathrm{a}$ & $10,10 \mathrm{a}$ & $95 \mathrm{a}$ & $90 \mathrm{a}$ & $69 \mathrm{bc}$ & $72 \mathrm{a}$ \\
\hline 2 dias CS & $12,42 \mathrm{a}$ & $11,91 \mathrm{bc}$ & $11,06 \mathrm{c}$ & $7,30 \mathrm{c}$ & $89 a b$ & $95 \mathrm{a}$ & $83 \mathrm{ab}$ & $72 \mathrm{a}$ \\
\hline 4 dias CS & $12,16 \mathrm{a}$ & $11,38 \mathrm{bc}$ & $11,81 \mathrm{c}$ & $8,04 \mathrm{abc}$ & $34 \mathrm{c}$ & $46 \mathrm{~b}$ & $67 \mathrm{bc}$ & $73 \mathrm{a}$ \\
\hline 6 dias CS & $13,22 \mathrm{a}$ & $10,18 \mathrm{c}$ & $14,43 \mathrm{~b}$ & $9,36 \mathrm{ab}$ & $89 \mathrm{ab}$ & $94 \mathrm{a}$ & $89 \mathrm{a}$ & $45 \mathrm{~b}$ \\
\hline CV (\%) & 7,24 & 6,65 & 5,14 & 11,43 & 7,37 & 11,23 & 7,94 & 9,63 \\
\hline
\end{tabular}

Médias seguidas pela mesma letra na coluna não diferem estatisticamente entre si pelo teste de Tukey a $5 \%$ de probabilidade (means followed by the same letter in column do not differ from each other according to Tukey's test, at 5\%). 
Tabela 3. Porcentagem de germinação (GER), primeira contagem de germinação (PC), velocidade de germinação (VG), porcentagem de emergência de plântulas (EME) e índice de velocidade de emergência (IVE) obtidas de sementes de repolho submetidas a diferentes tempos de envelhecimento artificial (EA), com (C) e sem (NC) osmocondicionamento \{germination (GER), first count of germination (PC), germination speed (VG), percentage of seedling emergence (EME) and speed emergence index (IVE) obtained from cabbage seed lots subjected to different times of artificial aging (EA) with (C) and without (NC) priming\}. Viçosa, UFV, 2014.

\begin{tabular}{|c|c|c|c|c|c|c|}
\hline \multirow{2}{*}{ EA (h) } & \multicolumn{2}{|c|}{ GER (\%) } & \multicolumn{2}{|c|}{ PC (\%) } & \multicolumn{2}{|c|}{ VG (dias) } \\
\hline & $\mathrm{NC}$ & $\mathrm{C}$ & $\mathrm{NC}$ & $\mathrm{C}$ & $\mathrm{NC}$ & $\mathrm{C}$ \\
\hline 0 & $98 \mathrm{Aa}$ & $98 \mathrm{Aa}$ & $94 \mathrm{Aa}$ & $90 \mathrm{Aa}$ & $24,4 \mathrm{Aa}$ & $24,4 \mathrm{Aa}$ \\
\hline 24 & $76 \mathrm{Ab}$ & $79 \mathrm{Ab}$ & $70 \mathrm{Ab}$ & $63 \mathrm{Ab}$ & 24,1 Aa & $22,8 \mathrm{Aab}$ \\
\hline 33 & $59 \mathrm{Bc}$ & $72 \mathrm{Ab}$ & $42 \mathrm{Bc}$ & $56 \mathrm{Ab}$ & $22,0 \mathrm{Ba}$ & $24,5 \mathrm{Aa}$ \\
\hline 42 & $58 \mathrm{Bc}$ & $73 \mathrm{Ab}$ & $28 \mathrm{Bc}$ & $55 \mathrm{Ab}$ & $17,5 \mathrm{Bb}$ & $20,2 \mathrm{Ab}$ \\
\hline \multirow[t]{3}{*}{$\mathrm{CV}(\%)$} & \multicolumn{2}{|c|}{8,79} & \multicolumn{2}{|c|}{10,66} & \multicolumn{2}{|c|}{6,12} \\
\hline & \multicolumn{3}{|c|}{ EME (\%) } & \multicolumn{3}{|c|}{ IVE } \\
\hline & $\mathrm{NC}$ & \multirow{2}{*}{\multicolumn{2}{|c|}{ C }} & \multicolumn{2}{|c|}{$\mathrm{NC}$} & $\mathrm{C}$ \\
\hline 0 & $81 \mathrm{Aa}$ & & & \multicolumn{2}{|c|}{$5,3 \mathrm{Bab}$} & $6,6 \mathrm{Aa}$ \\
\hline 24 & $90 \mathrm{Aa}$ & \multicolumn{2}{|c|}{$\begin{array}{l}91 \text { Aa } \\
03 \mathrm{Aa}\end{array}$} & \multicolumn{2}{|c|}{$5,5 \mathrm{Aa}$} & $5,9 \mathrm{Aab}$ \\
\hline 33 & $83 \mathrm{Aa}$ & \multicolumn{2}{|c|}{$94 \mathrm{Aa}$} & \multicolumn{2}{|c|}{ 4,8 $\mathrm{Bab}$} & 6,2 Aab \\
\hline 42 & $60 \mathrm{Ab}$ & \multicolumn{2}{|c|}{$71 \mathrm{Ab}$} & & & $5,0 \mathrm{Ab}$ \\
\hline CV (\%) & \multicolumn{3}{|c|}{8,85} & \multicolumn{3}{|c|}{9,36} \\
\hline
\end{tabular}

Médias seguidas pela mesma letra minúscula na coluna, não diferem entre si pelo teste de Tukey a 5\% de probabilidade; médias seguidas pela mesma letra maiúscula na linha, não diferem entre si pelo teste $\mathrm{F}$ a $5 \%$ de probabilidade (means followed by the same lowercase letter in column do not differ from each other according to Tukey's test at $5 \%$; means followed by the same uppercase letter in line do not differ from each other according to $\mathrm{F}$ test, at $5 \%$ ).

a germinação seja mais rápida. Assim, no presente trabalho, esses mecanismos podem ter sido ativados nas sementes, de forma mais evidente para os lotes de menor qualidade fisiológica.

Além disso, segundo Bray (1995), o condicionamento osmótico leva as sementes a um ponto muito próximo da germinação, permitindo, assim, a completa passagem pelas fases I e II de absorção de água, além da extensão da fase II, em que ocorre o mecanismo pré-germinativo de reparo das macromoléculas e outras estruturas celulares, o que explica o fato de se obter maior porcentagem de germinação em lotes de sementes condicionados.

Assim, as sementes de baixo vigor, não submetidas ao tratamento de condicionamento, com germinação mais lenta comparadas às condicionadas, podem não ter tido tempo hábil para germinar dentro do período de duração do teste de germinação, que no caso do repolho é de 10 dias (Brasil, 2009). Isso pode ocorrer devido ao tempo e energia despendidos durante a atuação dos mecanismos de reparo nessas sementes.
Nas sementes submetidas a tratamentos de condicionamento osmótico, os mecanismos de reparo já atuaram e elas estão muito próximas da fase final de germinação, o que pode favorecer a obtenção de maior velocidade de germinação.

Em geral, não houve efeito do condicionamento osmótico na porcentagem de emergência de plântulas em condições de casa de vegetação, para os lotes 1, 2 e 4 (Tabela 2). Contudo, observa-se para o lote 1 , porcentagem de emergência maior em 12 pontos percentuais para as sementes osmocondicionadas em PEG 6000 a -1,0 MPa por 6 dias, sem secagem, em relação à testemunha. Efeitos positivos do condicionamento osmótico na porcentagem de emergência de plântulas foram observados para as sementes do lote 3 , em que o condicionamento em PEG 6000 por 2 e 6 dias, com secagem, e por 4 dias, sem a secagem das sementes, foram superiores à testemunha. Nota-se que o menor valor de porcentagem de emergência de plântulas foi observado para as sementes deste lote (Tabela 1); porém, após o condicionamento osmótico por 6 dias, seguido de secagem das sementes, houve um incremento de 30 pontos percentuais na emergência de plântulas, valor este expressivo quando se consideram as vantagens de se obter uma população de plantas adequada em campo.

De modo geral, não houve efeito do condicionamento osmótico na porcentagem de germinação e primeira contagem de germinação (Tabela 2) dos lotes 1 e 2 , classificados como mais vigorosos. Para os lotes menos vigorosos (lotes 3 e 4), em geral, foram obtidos maiores valores de germinação e de velocidade de germinação (Tabela 2), principalmente quando condicionadas por seis dias, com e sem secagem após o tratamento. No entanto, segundo Balbinot \& Lopes (2006), a secagem das sementes após o tratamento de condicionamento é desejável, porque facilita seu manuseio e armazenamento, podendo ser indicada para sementes de repolho.

\section{Ensaio 2}

Para comprovar o efeito do tratamento de condicionamento fisiológico indicado na primeira etapa do trabalho (Ensaio 1), condicionamento com PEG 6000 a $-1,0 \mathrm{MPa}$, a $20^{\circ} \mathrm{C}$, durante 6 dias, seguido de secagem, efetuou-se a deterioração artificial de um lote de sementes de repolho, por diferentes períodos, resultando em quatro lotes com qualidade fisiológica contrastante.

Os dados referentes à qualidade fisiológica das sementes de repolho submetidas ao envelhecimento artificial, osmocondicionadas ou não, estão apresentados na Tabela 3. O envelhecimento artificial permitiu obter sementes com diferentes níveis de deterioração e, consequentemente, vigor.

As sementes não envelhecidas apresentaram germinação superior às envelhecidas por 24, 33 e 42 horas, tanto nas sementes condicionadas como nas não condicionadas (Tabela 3). Não houve efeito do condicionamento osmótico em lotes de sementes não envelhecidas ou quando envelhecidas por $24 \mathrm{~h}$. A partir deste período de envelhecimento, verificou-se maior porcentagem de germinação para as sementes osmocondicionadas em relação às não condicionadas.

Os maiores valores de germinação, 
que no caso do presente trabalho consiste na porcentagem de plântulas normais, obtidos para as sementes submetidas aos maiores períodos de envelhecimento artificial (33 e 42 horas), e submetidas ao condicionamento osmótico, podem estar relacionados à atuação dos mecanismos de reparo nas sementes durante o tratamento de condicionamento (Srinivasan et al., 1999). Assim, nas sementes não condicionadas, esses mecanismos não atuaram, o que contribuiu para apresentarem menor porcentagem de plântulas normais. Resultados semelhantes foram observados para o vigor das sementes, quando avaliado pelos testes de primeira contagem de germinação e velocidade de germinação (Tabela 3).

Ao se comparar sementes com e sem osmocondicionamento, observa-se que este tratamento não afetou a porcentagem de emergência das plântulas. Pelos dados de germinação, foi possível observar efeito benéfico do condicionamento osmótico, principalmente nas sementes envelhecidas por maior período. Apesar disso, pelos dados de emergência, não foi possível observar esse efeito. Provavelmente, o tempo de duração do teste de emergência (12 dias) foi suficiente para que, mesmo para as sementes mais deterioradas e que demandaram mais tempo para a germinação, fosse possível a emergência das plântulas. Quanto ao teste de germinação, este teve duração de 10 dias (Brasil, 2009) e, ainda, foram avaliadas as características morfológicas das plântulas, computando-se para o cálculo da porcentagem de germinação apenas as que foram classificadas como normais. Dessa forma, para a emergência de plântulas, foram observados maiores valores, comparados aos de germinação. Assim, o efeito do condicionamento ficou evidente na velocidade e não na porcentagem final de emergência de plântulas (Tabela 3).

No presente trabalho, foram observadas maiores velocidades de germinação e de emergência de plântulas quando sementes envelhecidas por $42 \mathrm{~h}$ foram osmocondicionadas, comparadas à testemunha não condicionada. Nos demais tratamentos de envelhecimento, não houve diferença entre sementes condicionadas e não condicionadas. Assim, pode-se afirmar que, sementes em estádio mais avançado de deterioração, como é o caso daquelas envelhecidas por maior tempo (42 h), podem ser beneficiadas pelo condicionamento osmótico (Tabela 3).

Em geral, verifica-se pelos resultados obtidos nos testes de germinação e primeira contagem da germinação o benefício do osmocondicionamento em sementes envelhecidas artificialmente nos períodos de 33 e 42 horas (Tabela $3)$. No presente trabalho, as sementes de menor vigor submetidas ao condicionamento osmótico apresentaram desempenho superior comparado às não condicionadas.

Há relatos de que danos severos que ocorrem na fase que precede a morte da semente são irreversíveis, não sendo possível que processos de reparo celular eficientes ocorram (Lanteri et al., 2000). Assim, dependendo da espécie, lotes de sementes com qualidade fisiológica distinta podem responder diferentemente ao condicionamento osmótico (Kikuti \& Marcos-Filho, 2009). Considerando-se que o osmocondicionamento tem por objetivo uniformizar o comportamento de indivíduos componentes de uma população (Nascimento, 2004), lotes compostos por sementes em avançado estádio de deterioração podem não responder adequadamente ao condicionamento fisiológico. Da mesma forma, geralmente, não há benefícios para lotes altamente vigorosos.

Portanto, pode-se concluir que o condicionamento osmótico em solução aerada de PEG 6000 a -1,0 MPa, por seis dias, é benéfico para sementes de repolho, sendo que até o momento não havia informações conclusivas sobre a indicação de tratamentos de condicionamento fisiológico para sementes dessa espécie. Os efeitos positivos do condicionamento osmótico na germinação e no vigor das sementes são mais evidentes em lotes de menor qualidade fisiológica. Assim, esse tratamento pode ser indicado para utilização pelas empresas produtoras de sementes de repolho para uniformizar e acelerar a germinação das sementes dos lotes comercializados.

\section{REFERÊNCIAS}

BALBINOT, E; LOPES, HM. 2006. Efeitos do condicionamento fisiológico e da secagem na germinação e no vigor de sementes de cenoura. Revista Brasileira de Sementes 28: 01-08.

BEWLEY, JD; BLACK, M. 1994. Seeds: Physiology of development and germination. 2. ed. New York: Plenum Press. 445p.

BITTENCOURT, M; DIAS, D; DIAS, L; ARAÚJO, E. 2005. Germination and vigour of primed asparagus seeds. Scientia Agricola 62: 319-324.

BRASIL. 2009. Ministério da Agricultura, Pecuária e Abastecimento. Regras para análise de sementes. Secretaria de Defesa Agropecuária. Brasília-DF: MAPA/ACS. 395p.

BRAY, CM. 1995. Biochemical processes during the osmopriming of seeds. In: KIGEL, J; GALILI, G (eds). Seed development and germination. New York: Marcel Dekker, Inc. p.767-789.

CASEIRO, RF; MARCOS-FILHO, J. 2005. Métodos para a secagem de sementes de cebola submetidas ao condicionamento fisiológico. Horticultura Brasileira 23: 887-892.

DIAS, DCS; PAIXÃO, GP; SEDIYAMA, MAN; CECON, PR. 1999. Pré-condicionamento de sementes de quiabo: efeitos na qualidade fisiológica e no potencial de armazenamento. Revista Brasileira de Sementes 21: 224-231.

FANAN, S; NOVEMBRE, ADLC. 2007. Condicionamento fisiológico de sementes de berinjela. Bragantia 66: 675-683.

FINCH-SAVAGE, NE; MCKEE, JMT. 1990. The influence of seed quality and pregermination treatment on cauliflower and cabbage transplant production and field growth. Annals of Applied Biology 116: 365-369.

GOMES, DP; SILVA, AF; DIAS, DCFS; ALVARENGA, EM; SILVA, LJ; PANOZZO, LE. 2012. Priming and drying on the physiological quality of eggplant seeds. Horticultura Brasileira 30: 484-488.

KIKUTI, ALP; MARCOS-FILHO, J. 2009. Condicionamento fisiológico de sementes de couve-flor. Horticultura Brasileira 27: 240-245.

LANTERI, S; PORTIS, E; BERGERVOET, HW; GROOT, SPC. 2000. Molecular markers for the priming of pepper seeds (Capsicum annuит L.). Journal of Horticultural Science and Biotecnology 75: 607-611.

MAGUIRE, JD. 1962. Speed of germination aid in selection and evaluation for seeding and vigour. Crop Science 2: 176-177.

MARCOS-FILHO, J; KIKUTI, ALP. 2008. Condicionamento fisiológico de sementes de couve-flor e desempenho das plantas em campo. Horticultura Brasileira 26: 165-169.

NASCIMENTO, WM. 2004. Condicionamento osmótico de sementes de hortaliças. Brasília: Embrapa. 12p. (Circular Técnica 33).

NASCIMENTO, WM. 2005. Condicionamento osmótico de sementes de hortaliças visando 
a germinação em condições de temperaturas baixas. Horticultura Brasileira 23: 211-214.

PARERA, C; CANTLIFFE, D. 1994. Presowing seed priming. Horticultural Reviews 16: 109-139.

PEREIRA, MD; SANTOS, DCF; DIAS, LAS; ARAUJO, EF. 2008. Germinação e vigor de sementes de cenoura osmocondicionadas em papel umedecido e solução aerada. Revista Brasileira de Sementes 30: 137-145.

POWELL, AA; THORNTON, JM; MITCHELL, A. 1991. Vigour differences in brassica seed and their significance to emergence and seedling variability. Journal of Agricultural Science 116: 369-373.
ROWSE, HR. 1996. Drum priming - a nonosmotic method of priming seeds. Seed Science and Technology 24: 281-294.

SRINIVASAN, K; SAXENA, S; SINGH, BB. 1999. Osmo and hydropriming of mustard seeds to improve vigour and some biochemical activities. Seed Science and Technology 27: 785-793. 